AperTO - Archivio Istituzionale Open Access dell'Università di Torino

\title{
Cooling dynamics: a new predictor of long-term efficacy of atrioventricular nodal reentrant tachycardia cryoablation
}

\section{This is the author's manuscript}

Original Citation:

Availability:

This version is available http://hdl.handle.net/2318/1624216

since 2017-04-20T15:20:47Z

Published version:

DOI:10.1007/s10840-016-0208-4

Terms of use:

Open Access

Anyone can freely access the full text of works made available as "Open Access". Works made available under a Creative Commons license can be used according to the terms and conditions of said license. Use of all other works requires consent of the right holder (author or publisher) if not exempted from copyright protection by the applicable law. 
This is the author's final version of the contribution published as:

Matta, Mario; Anselmino, Matteo; Scaglione, Marco; Vitolo, Marco; Ferraris, Federico; Di Donna, Paolo; Caponi, Domenico; Castagno, Davide; Gaita, Fiorenzo. Cooling dynamics: a new predictor of long-term efficacy of atrioventricular nodal reentrant tachycardia cryoablation. JOURNAL OF INTERVENTIONAL CARDIAC ELECTROPHYSIOLOGY. 48 (3) pp: 333-341.

DOI: $10.1007 / \mathrm{s} 10840-016-0208-4$

The publisher's version is available at:

http://link.springer.com/10.1007/s10840-016-0208-4

When citing, please refer to the published version.

Link to this full text:

http://hdl.handle.net/2318/1624216 
Cooling dynamics: a new predictor of long-term efficacy of atrioventricular nodal reentrant tachycardia cryoablation

Mario Matta, MD*, Matteo Anselmino, MD PhD*, Marco Scaglione, MD , Marco Vitolo, MD*, Federico Ferraris, MD*, Paolo Di Donna, MDS, Domenico Caponi, MD $\int$, Davide Castagno, MD PhD*, Fiorenzo Gaita, MD Prof*.

*Division of Cardiology, Department of Medical Sciences, òCittà della Salute e della Scienzaò Hospital, University of Turin, Italy

§Division of Cardiology, Cardinal Massaia Hospital, Asti, Italy

Word count: 3,931 words, 5 Tables, 3 Figures, 30 References

Key words: supraventricular tachycardia, AVNRT, cryoablation, slow pathway, cooling dynamics Running title: long-term outcome of AVNRT cryoablation

Corresponding Author:

Mario Matta, MD

Cardiology Division, Department of Medical Sciences,

ñCittà della Salute e della Scienzaò Hospital

University of Turin

Corso Bramante 88, 10126 Turin, Italy

Phone: +39-0116335570 Fax: +39-0116966015

Email: $\underline{\text { m.matta26@gmail.com }}$ 


\begin{abstract}
Purpose. Catheter ablation of the slow pathway is the most effective treatment for atrioventricular nodal reentrant tachycardia (AVNRT). Cryoenergy, compared to radiofrequency, relates to lower heart block risk, but higher incidence of AVNRT recurrences. The aim of this study is to confirm safety and efficacy of AVNRT cryoablation and to identify predictors of long-term recurrences.
\end{abstract} Methods and Results. Among 241 patients undergoing AVNRT cryoablation, 239 (99.2\%) experienced acute effective cryoablation of the slow pathway, and no procedure-related

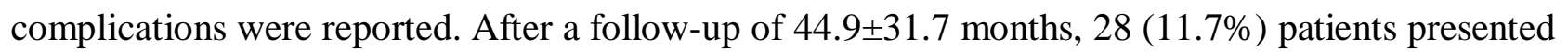
AVNRT recurrences. A shorter pre-ablation $(\mathrm{p}=0.05)$ and post-ablation anterograde Wenckebach cycle length $(\mathrm{p}<0.01)$, a shorter post-ablation atrioventricular node refractory period $(\mathrm{p}=0.04)$ and persistence of the crossover sign $(\mathrm{p}=0.03)$ were associated with higher incidence of long-term recurrences. Considering cooling dynamics, a longer time to reach temperature $\mathrm{O} 70^{\circ} \mathrm{C}(\mathrm{p}=0.03)$ and a higher minimal temperature during ablation $(\mathrm{p}=0.04)$ related to recurrences. Patients without residual markers of dual AV node physiology (AH jump, single atrial echo beat, crossover) reported a lower recurrence rate $(\mathrm{p}=0.05)$ compared to those without. At multivariate analysis, a longer time to $-70^{\circ} \mathrm{C}$ was the strongest independent predictor of long-term recurrence (OR $1.75,95 \%$ IC 1.01 $3.03, \mathrm{p}=0.04)$.

Conclusions. AVNRT cryoablation is safe and effective. Long-term recurrence rate was $11.7 \%$. An ablation approach directed to the complete elimination of dual AV node physiology, along with assessment of tissueâs cooling dynamics, hold the potential to improve long-term AVNRT cryoablation efficacy.

Abstract word count: 244 


\section{Introduction}

Atrioventricular nodal reentrant tachycardia (AVNRT) is the most common paroxysmal supraventricular tachycardia. The underlying electrophysiological mechanism is the presence of a dual atrioventricular (AV) node physiology, including a fast and a slow pathway [1], characterized by different refractory periods. Dual AV node physiology is a frequent finding, being described in up to $90 \%$ of patients in a small case sample of heavily sedated patients undergoing electrophysiological study (EPS) [2], but does not always imply an AVNRT. Radiofrequency transcatheter ablation (RFCA) of the slow pathway is at present considered the first choice treatment for AVNRT because of its high acute and long-term efficacy [3]. Although RFCA is widely used, it is still associated with a risk of irreversible complete AV block (up to 1-2\%) [4]. Transcatheter cryoablation of the slow pathway has been demonstrated to be a feasible and safe alternative to RFCA, with no permanent AV block reported and a comparable acute success rate [57]. In fact, reversible cryomapping permits to evaluate the safety of the site targeted for ablation, leading to a return to integrity in case of AV block development [8]. However, the long-term recurrence rate of this technique remains higher than RFCA $[9,10]$.

Previous studies focused on identifying factors that could affect acute and long-term efficacy, such as catheter tip size [11], electrophysiological markers of residual dual AV node physiology [11,12], duration and number of cryoenergy applications [13], but data are limited and sometimes controversial, and no strong predictor of cryoablation long-term efficacy has been identified [1416]. The aim of this study is to evaluate the safety, acute and long-term efficacy of AVNRT cryoablation and to identify intra-procedural predictors of long-term efficacy, focusing on both electrophysiological parameters and cooling dynamics. 


\section{Methods}

We retrospectively analyzed all patients with diagnosis of AVNRT confirmed by EPS who underwent transcatheter cryoablation of the slow pathway from June 2005 to March 2015 in two high volume Centers, both performing cryoablation as a standard first-line approach for AVNRT ablation. Inclusion criteria were: one or more previously documented episodes of AVNRT (12-leads ECG or Holter ECG monitoring documentation), clinical response to vagal manoeuvers and/or i.v. adenosine or $\mathrm{AV}$ node blocking drugs, and written informed consent to undergo the ablation procedure. Patients in whom cryoablation was performed using a 4-mm tip catheter, previously described as less effective than 6-mm tip, were excluded from the analysis.

\section{Electrophysiological study and cryoablation procedure}

Written informed consent was obtained from all individual participants included in the study. A standard EPS including ventricular and atrial programmed and incremental stimulation, was performed to evaluate dual AV node physiology and confirm the diagnosis of AVNRT. All antiarrhythmic drugs (AAD) were discontinued for at least five half-lives before EPS. Diagnostic catheters were positioned in His bundle region, right ventricular apex and coronary sinus through a venous femoral approach. Recently, NavX (St. Jude Medical, St. Paul, MN, USA) system was used in order to minimize the use of fluoroscopy and to perform a right atrium electroanatomical map [17].

Dual AV nodal physiology was defined as the presence of a Ó50 ms increase in A2H2 in response to a $10 \mathrm{~ms}$ decrease of the extrastimulus at programmed atrial or ventricular stimulation (jump). Incremental atrial stimulation was performed to assess anterograde Wenckebach cycle length and the PR to RR interval ratio at the maximum rate with consistent $1: 1 \mathrm{AV}$ conduction (a PR to RR ratio higher than 1 at the maximal 1:1 AV conduction heart rate will be referred as crossover sign) $[18,19]$. 
If sustained AVNRT was not inducible, intravenous isoproterenol was administered to facilitate induction until a $20 \%$ increase in baseline heart rate was detected. After tachycardia induction, a single premature ventricular extrastimulus was administered to rule out the presence of an accessory pathway and to confirm the subtype (typical vs atypical) of the AVRNT. Patients in whom sustained AVNRT was not inducible slow pathway ablation was performed only in case of undoubtful 12-leads ECG documentation of AVNRT and concomitant dual AV node physiology (AH jump, echo beats and crossover sign). Subsequently, a 6-mm cryocatheter (Freezor Xtra, Cryocath Technologies, Medtronic, Montreal, Canada) was used to perform slow pathway cryoablation. An electroanatomical approach was applied to identify the target site through the recording and validation of slow pathway potential [20].

Cryomapping $\left(-30{ }^{\circ} \mathrm{C}\right.$ for $\left.60 \mathrm{sec}\right)$ was performed in order to verify safety and efficacy of the site. In case of successful cryomapping (AVNRT non-inducibility or absence of dual AV nodal physiology without affecting anterograde AV conduction), cryoablation was performed $\left(-75 /-80^{\circ} \mathrm{C}\right)$ by a single 8-minutes application to create a permanent lesion; a 4-minutes bonus lesion was always applied in an adjacent site [21]. EPS on and off isoproterenol was repeated 20 minutes after cryoablation to assess non-inducibility of AVNRT and absence of dual AV node physiology; residual AH jump with or without a single nodal echo beat was accepted only in cases where a previously inducible AVNRT was not anymore inducible, on and off isoproterenol. Baseline and post-ablation EPS parameters were recorded and analyzed for all patients.

Additionally, cooling dynamics characteristics of the effective cryoenergy application (defined as the application immediately followed by dual AV node physiology disappearance or slow pathway significant modulation, i.e., disappearance of AVNRT induction, echo beats, AH jump or crossover sign), including time to reach the therapeutic temperature of $-70^{\circ} \mathrm{C}$ starting from cryomapping, the minimal temperature during ablation and the presence/absence of a temperature curve inversion during progression from cryomapping to cryoablation were analyzed in all procedures. 
All the patients were discharged without AAD the day after procedure, and underwent clinical evaluation, including ECG and 24h-Holter recording at 3, 6 and 12 months after cryoablation. In case of documented AVNRT recurrence, a new cryoablation procedure was planned. An additional follow-up visit was performed at the end of follow-up.

\section{Statistical analysis}

Continuous data, expressed as means \pm standard deviation (SD), were compared by one-way ANOVA test after normal distribution was confirmed. Categorical variables, presented as counts and percentages, were compared in cross-tabulation tables by Pearsonôs chi-square test. Following univariate analysis, all parameters with associated $\mathrm{p}$ value $<0.05$ were tested in a multivariable logistic regression model used to determine the association between baseline and procedural characteristics and arrhythmic recurrences during follow-up. All tests of significance were twotailed, and a p value <0.05 was considered statistical significant. All analyses were performed using SPSS 21.0.

\section{Results}

Study population included 241 patients with symptomatic episodes of AVNRT who underwent cryoablation of the slow pathway. Acute success was achieved in 239 patients (99.2\%). During a mean follow-up of $44.9 \pm 31.7$ months, $28(11.7 \%)$ patients experienced AVNRT recurrence.

Mean age was $47.5 \pm 19.7$ years, and $149(61.8 \%)$ patients were females. Most patients (92.5\%) did not have structural heart disease, or any other associated arrhythmia. Fifty-seven (23.7\%) patients suffered from hypertension, $5(2.1 \%)$ from hyperthyroidism and 13 (5.4\%) from hypothyroidism. AAD therapy before cryoablation included beta-blockers in 107 (44.4\%) patients, Calcium channel blockers in $25(10.4 \%)$ patients and class Ic AAD in 48 (19.9\%) patients. Typical (slow-fast) AVNRT was diagnosed in $229(95 \%)$ patients. Baseline characteristics are shown in Table 1. 
In $203(84.9 \%)$ patients sustained AVNRT was induced during EPS, off (79\%) or on (21\%) isoproterenol infusion. All patients presented a dual AV node physiology, in baseline study or during isoproterenol infusion. Due to the undoubtful ECG documentation and the presence of dual AV node physiology at EPS, slow pathway ablation was performed also in the $36(15.1 \%)$ patients without sustained AVNRT induction. Recurrence rate did not differ between patients in which sustained AVNRT was induced or not at EPS ( $\mathrm{p}=0.19)$. Baseline EPS parameters are reported in Table 2.

A median of $3.3 \pm 2.8$ cryoenergy applications were performed per patient, with a mean duration of $7.8 \pm 0.5 \mathrm{~min}$. Mean fluoroscopy time was $4.5 \pm 5.0 \mathrm{~min}$. Cooling dynamics characteristics, in particular time to reach the target temperature of $-70^{\circ} \mathrm{C}$, minimal temperature reached and presence/absence of a transitory temperature curve inversion are reported in Table 3 . None of the patients had procedure-related complications, in particular no AV conduction abnormalities were reported.

At post-ablation EPS (Table 4), 51 (21.3\%) patients reported a residual AH jump, 19 (7.9\%) a single nodal echo beat, and 9 (3.8\%) residual crossover sign. AV nodal anterograde refractory period was $312.6 \pm 77.5 \mathrm{~ms}$ after cryoablation, and the anterograde Wenckebach cycle length 370.4 $\pm 82.2 \mathrm{~ms}$. At the end of the procedure in $238(99.2 \%)$ patients AVNRT was not inducible on and off isoproterenol, and the procedure was considered effective. AVNRT was still inducible in one patient, in whom modulation of the slow pathway was performed (this patient did not suffer recurrences during follow-up).

\section{Predictors of recurrence}

No differences were observed in baseline clinical characteristics between patients who had or not

recurrences. Considering cooling dynamics, a longer time to reach a temperature $\mathrm{O}-70^{\circ} \mathrm{C}$ during ablation $(8.9 \pm 4.4$ vs $7.3 \pm 2.5 \mathrm{sec}, \mathrm{p}=0.03)$ and a higher minimal temperature during ablation $(-78$ \pm 2.5 vs $-79.2 \pm 2.3{ }^{\circ} \mathrm{C}, \mathrm{p}=0.04$ ) related to a higher incidence of AVNRT recurrence. As shown in 
the Kaplan-Meier estimate of survival (Figure 1), patients without any marker of residual dual AV node physiology (AH jump, single nodal echo beat, crossover sign) at final EPS reported a lower recurrence rate $(\mathrm{p}=0.05)$ compared to patients with at least one of these markers.

At multivariate analysis, a longer time to $-70^{\circ} \mathrm{C}$ proved to be the strongest independent predictor of long term recurrence (OR 1.75, 95\% IC 1.01 - 3.03, p= 0.04) (Table 5).

Additionally, a shorter pre-ablation $(325.4 \pm 54.02$ vs $356.9 \pm 76.3 \mathrm{~ms}, \mathrm{p}=0.05)$ and post-ablation anterograde Wenckebach cycle length (332 \pm 69.6 vs $375.5 \pm 82.5 \mathrm{~ms}, \mathrm{p}<0.01)$, a shorter AV node refractory period after ablation $(261.8 \pm 63.7 \mathrm{vs} 312.66 \pm 77.5 \mathrm{~ms}, \mathrm{p}=0.04)$ and persistence of the crossover $(10.7 \%$ vs $2.8 \%, \mathrm{p}=0.03)$ were related to a higher incidence of long-term recurrences.

\section{Discussion}

Our results show that slow pathway cryoablation for AVNRT is an effective and safe technique, with an acute efficacy rate of $99.2 \%$ (comparable to that reported by RFCA) and no AV block reported. Considering long-term outcome, the incidence of recurrences $(11.7 \%)$ is higher compared to that reported by RFCA, ranging from 2 to $4 \%[4,7,9,10]$. Interestingly, a cooling dynamic pattern characterized by longer cooling time during ablation and the presence of residual dual AV node physiology appear to be strong predictors of long term AVNRT recurrence.

Incidence of AV block following AVNRT RFCA has been reported to occur in a percentage of patients of about $0.5-2 \%$ [7,22,23], and a large meta-analysis reporting an incidence of $1.7 \%$ [10]. To avoid this risk, cryoablation offers patients a potentially safer alternative to RFCA, due to the advantages offered from cryomapping: the transient application of $-30^{\circ} \mathrm{C}$ is useful to assess the safety and efficacy of the site, as the appearance of AV block can be completely reversed by cryomapping interruption. Recently, a large study including over 1,000 AVNRT patients undergoing cryoablation, in fact, confirmed that this technique may present a slightly lower efficacy than RFCA, but is indeed safer in terms of incidence of AV block [6]. Indeed, considering the 
usually young age of the patients and the benign course of AVNRT, the potential higher need of repeated procedures following cryoablation may be worth since it is counterbalanced by the clearly reduced risk of permanent AV block. The present study confirms these previous findings, but is mostly focused on predictor of recurrence, analyzing in addition an original parameter, cooling dynamics, which plays a relevant role in influencing long-term outcome of AVNRT cryoablation.

\section{Cooling dynamics}

Previous studies investigated the impact of the number and duration of cryoenergy applications on cryoablation efficacy, in particular addressing the higher incidence of recurrence compared to RFCA [24].

This difference is due to the mechanisms of lesion formation of the two energy sources. Compared to RFCA, cryoablation produces a smaller and more circumscribed lesion, mainly due to the adherence of the catheter to the endocardium during the application [25]. Overall, several factors have been investigated. It has been shown that the use of 6-mm tip catheters relates to a lower recurrence rate compared to 4 -mm tip $[11,26]$. On the other hand, the role of number and duration of cryoenergy applications on long-term outcome is controversial $[15,27,28]$. Notably, our results suggest that the quality of the cooling dynamics may be assessed and seems more relevant compared to the general quantity of cryoenergy delivered. The quality of cryoenergy application,

easily monitored in real time during the procedure, as the time to reach temperature $\mathrm{O}-70^{\circ} \mathrm{C}$ and the lower minimal absolute temperature, emerged as a strong candidate to improve long-term outcome. As showed in Figure 2, despite a certain amount of overlap, likely due to the bias deriving from the chosen site for ablation, a longer time to reach target temperature, such as 10 seconds, is likely related to ineffective cryoenergy applications. A slower time to reach therapeutic temperature, as experienced in many patients suffering from AVNRT recurrences (Figure 3), may in fact be due to 
a suboptimal contact of the catheter tip to the endocardium, leading to ineffective lesions in the long run. Indeed, the presence of a contact force sensing tool, as available for most radiofrequency ablation catheters, would probably improve the outcome of the procedure by ensuring optimal catheter-tissue contact assessment. However, in the absence of this potential implementation, cooling dynamics seems a relevant factor to consider, candidating perhaps, to acutely guide the procedure, and, in any case, warranting further prospective investigations.

\section{Residual slow pathway conduction}

Several studies suggest that the persistence of residual slow pathway conduction, identified by EPS markers such as AH jump, AV nodal single echo beat and crossover sign, may relate to a higher AVNRT recurrence rate. De Sisti et al. [12] in a large series of patients reported that slow pathway complete suppression relates to improved outcome, and a single nodal echo beat or residual AH jump are associated with a slightly higher incidence of recurrence, and the same results were reported by Bastani et al. [29]. Feldman et al. [30] reported that a single AV nodal echo beat did not predict AVNRT recurrence, but a large echo window is, indeed, associated with higher risk of recurrence.

The present study shows that residual AH jump and single AV nodal echo beat do not relate to higher risk of recurrence (probably due to the small number of patients with residual dual AV node physiology compared to the baseline population), but the persistence of crossover sign, when present, is significantly related with AVNRT recurrence. In fact, crossover is reported as a specific sign of dual AV node physiology, though not strongly sensitive. Moreover, a shorter Wenckebach cycle length and a shorter AV node refractory period at post-ablation EPS, signs of a residual slow pathway dormant conduction, relate to higher incidence of recurrence. Additionally, merging together the aforementioned markers of dual AV node physiology, Kaplan-Meier estimate of 
survival reports a lower incidence of AVNRT recurrence in patients with none compared to those with at least one of these marker $(\mathrm{p}=0.05)$. Our data suggest therefore that a more aggressive strategy directed to complete elimination of dual AV node physiology (absence of AH jump, single nodal echo beat and crossover) could potentially improve long-term efficacy.

\section{Limitations}

The retrospective nature of the study may limit its strength due to the absence of a prospective design and follow-up. However, the inclusion of all patients referred for AVNRT ablation, in two centers that regularly perform cryoablation in all patients as first-line treatment, avoids the possible bias deriving from individual energy source choice following the demonstration of patientsô anatomy. The relatively limited number of included patients may have impacted the statistical relevance of some EPS parameters. Additionally, the design of the study does not permit to define a cut-off for time to target temperature aiming to guarantee an effective lesion; however, longer time intervals (more than 10 seconds) to reach target temperature could, indeed, identify ineffective applications. The role of these markers of adherence to the target tissue, based on the temperature outputs derived from the commercial cryo-console, however, need to be prospectively tested to precisely define their role in predicting long-term outcome.

\section{Conclusions}

Transcatheter cryoablation of the slow pathway in patients suffering from AVNRT is a safe and effective procedure, and it is likely to be reproducibly performed without relevant risks. Although characterized by a relatively low incidence of long-term recurrences, its long-term efficacy is lower than RFCA. New predictors, such as complete elimination of dual AV node physiology and especially an improvement in cooling dynamics quality assessed by a short time interval to reach 
the therapeutic temperature of $<-70^{\circ} \mathrm{C}$, will likely be related to an improvement in long-term outcome of AVNRT cryoablation.

\section{Conflict of Interest Disclosures}

The Authors declare that they have no conflict of interest. 


\section{References}

1. Denes P, Wu D, Dhingra RC, Chuquimia R, Rosen KM. Demonstration of dual A-V nodal pathways in patients with paroxysmal supraventricular tachycardia. Circulation. 1973;48:549-555.

2. Ho SY, McComb JM, Scott CD, Anderson RH. Morphology of the cardiac conduction system in patients with electrophysiologically proven dual atrioventricular nodal pathways. J Cardiovasc Electrophysiol. 1993;4:504-512.

3. Page RL, Joglar JA, Caldwell MA, Calkins H, Conti JB, Deal BJ, Estes NA 3rd, Field ME, Goldberger ZD, Hammill SC, Indik JH, Lindsay BD, Olshansky B, Russo AM, Shen WK, Tracy CM, Al-Khatib SM; Evidence Review Committee Chair. 2015 ACC/AHA/HRS Guideline for the Management of Adult Patients With Supraventricular Tachycardia: A Report of the American College of Cardiology/American Heart Association Task Force on Clinical Practice Guidelines and the Heart Rhythm Society. Circulation. 2016;133:e506-74.

4. Hanninen M, Yeung-Lai-Wah N, Massel D, Gula L, Skanes A, Yee R, Klein G, Manlucu J, Leong-Sit P. Cryoablation versus RF ablation for AVNRT: a meta-analysis and systematic review. J Cardiovasc Electrophysiol. 2013;24:1354-1360.

5. Riccardi R, Gaita F, Caponi D, Grossi S, Scaglione M, Caruzzo E, Di Donna P, Pistis G, Richiardi E, Giustetto C, Bocchiardo M. Percutaneous catheter cryothermal ablation of atrioventricular nodal re-entrant tachycardia: Efficacy and safety of a new ablation technique. Ital Heart J. 2003;4:35-43. 
6. Insulander P, Bastani H, Braunschweig F, Drca N, Gudmundsson K, Kenneback G, Sadigh B, Schwieler J, Tapanainen J, Jensen-Urstad M. Cryoablation of substrates adjacent to the atrioventricular node: Acute and long-term safety of 1303 ablation procedures. Europace. $2014 ; 16: 271-276$.

7. Deisenhofer I, Zrenner B, Yin YH, Pitschner HF, Kuniss M, Grossmann G, Stiller S, Luik A, Veltmann C, Frank J, Linner J, Estner HL, Pflaumer A, Wu J, von Bary C, Ucer E, Reents T, Tzeis S, Fichtner S, Kathan S, Karch MR, Jilek C, Ammar S, Kolb C, Liu ZC, Haller B, Schmitt C, Hessling G. Cryoablation versus radiofrequency energy for the ablation of atrioventricular nodal reentrant tachycardia (the Cyrano study): Results from a large multicenter prospective randomized trial. Circulation. 2010;122:2239-2245.

8. De Sisti A, Tonet J, Gueffaf F, Touil F, Leclercq JF, Aouate P, Lacotte J, Hidden-Lucet F, Frank R. Effects of inadvertent atrioventricular block on clinical outcomes during cryoablation of the slow pathway in the treatment of atrioventricular nodal re-entrant tachycardia. Europace. 2008;10:14211427.

9. Opel A, Murray S, Kamath N, Dhinoja M, Abrams D, Sporton S, Schilling R, Earley M. Cryoablation versus radiofrequency ablation for treatment of atrioventricular nodal reentrant tachycardia: Cryoablation with 6-mm-tip catheters is still less effective than radiofrequency ablation. Heart Rhythm. 2010;7:340-343.

10. Spector P, Reynolds MR, Calkins H, Sondhi M, Xu Y, Martin A, Williams CJ, Sledge I. Metaanalysis of ablation of atrial flutter and supraventricular tachycardia. Am J Cardiol. 2009;104:671677. 
11. Sandilands A, Boreham P, Pitts-Crick J, Cripps T. Impact of cryoablation catheter size on success rates in the treatment of atrioventricular nodal re-entry tachycardia in 160 patients with long-term follow-up. Europace. 2008;10:683-686.

12. De Sisti A, Tonet J, Amara W, Raguin D, Aouate P, Gueffaf F, Touil F, Hidden-Lucet F. Correlations between long-term results after cryoablation for atrioventricular nodal reentry tachycardia and a residual jump associated or not with a single echo. Europace. 2012;14:261-266.

13. Drago F, Silvetti MS, De Santis A, Grutter G, Andrew P. Lengthier cryoablation and a bonus cryoapplication is associated with improved efficacy for cryothermal catheter ablation of supraventricular tachycardias in children. J Interv Card Electrophysiol. 2006;16:191ї 198.

14. Gaita F, Montefusco A, Riccardi R, Scaglione M, Grossi S, Caponi D, Caruzzo E, Giustetto C, Bocchiardo M, Di Donna P.Acute and long-term outcome of transvenous cryothermal catheter ablation of supraventricular arrhythmias involving the perinodal region. J Cardiovasc Med (Hagerstown). 2006;7:785-792.

15. Schwagten B, Van Belle Y, Jordaens L. Cryoablation: How to improve results in atrioventricular nodal reentrant tachycardia ablation? Europace. 2010;12:1522-1525.

16. Khairy P, Novak PG, Guerra PG, Greiss I, Macle L, Roy D, Talajic M, Thibault B, Dubuc M. Cryothermal slow pathway modification for atrioventricular nodal reentrant tachycardia. Europace. 2007;9:909-914.

17. Scaglione M, Ebrille E, Caponi D, Blandino A, Di Donna P, Siboldi A, Bertero G, Anselmino M, Raimondo C, Sardi D, Gabbarini F, Marasini M, Gaita F. Single center experience of fluoroless 
AVNRT ablation guided by electroanatomic reconstruction in children and adolescents. PACE. 2013;36:1460-1467.

18. Zhang X, Fisher JD, Kim SG, Matos JA, Waspe LE, Johnson C. Comparison of ramp and stepwise incremental pacing in assessment of antegrade and retrograde conduction. Pacing Clin Electrophysiol. 1986;9:42-52.

19. Baker JH 2nd, Plumb VJ, Epstein AE, Kay GN. PR/RR interval ratio during rapid atrial pacing: a simple method for confirming the presence of slow AV nodal pathway conduction. J Cardiovasc Electrophysiol. 1996;7:287-294.

20. Haissaguerre M, Gaita F, Fischer B, Commenges D, Montserrat P, d'Ivernois C, Lemetayer P, Warin JF. Elimination of atrioventricular nodal reentrant tachycardia using discrete slow potentials to guide application of radiofrequency energy. Circulation. 1992;85:2162-2175.

21. Drago F, Silvetti MS, De Santis A, Grutter G, Andrew P. Lengthier cryoablation and a bonus cryoapplication is associated with improved efficacy for cryothermal catheter ablation of supraventricular tachycardias in children. J Interv Card Electrophysiol. 2006;16:191-8.

22. Delise P, Sitta N, Bonso A, Coro' L, Fantinel M, Mantovan R, Sciarra L, Zoppo F, Verlato R, Marras E, D'Este D. Pace mapping of Koch's triangle reduces risk of atrioventricular block during ablation of atrioventricular nodal reentrant tachycardia. J Cardiovasc Electrophysiol. 2005;16:3035. 
23. Santangeli P, Proietti R, Di Biase L, Bai R, Natale A. Cryoablation versus radiofrequency ablation of atrioventricular nodal re-entrant tachycardia. J Interv Card Electrophysiol. 2013;39:111119.

24. Pieragnoli P, Paoletti Perini A, Checchi L, Carrassa G, Giomi A, Carrai P, Michelucci A, Padeletti L, Ricciardi G. Cryoablation of typical AVNRT: Younger age and administration of bonus ablation favor long-term success. Heart Rhythm. 2015;12:2125-2131.

25. Andrade JG, Khairy P, Dubuc M. Catheter cryoablation: Biology and clinical uses. Circ Arrhythm Electrophysiol. 2013;6:218-227.

26. Rivard L, Dubuc M, Guerra PG, Novak P, Roy D, Macle L, Thibault B, Talajic M, Khairy P. Cryoablation outcomes for AV nodal reentrant tachycardia comparing 4-mm versus 6-mm electrode-tip catheters. Heart Rhythm. 2008;5:230-234.

27. Atienza F, Almendral J, Sanchez-Quintana D, Zaballos M, Murillo M, Jimeno C, Parra V, Fernandez-Aviles F. Cryoablation time-dependent dose-response effect at minimal temperatures (80 degrees C): An experimental study. Europace. 2009;11:1538-1545.

28. Tse HF, Ripley KL, Lee KL, Siu CW, Van Vleet JF, Pelkey WL, Lau CP. Effects of temporal application parameters on lesion dimensions during transvenous catheter cryoablation. J Cardiovasc Electrophysiol. 2005;16:201-204.

29. Bastani H, Schwieler J, Insulander P, Tabrizi F, Braunschweig F, Kennebäck G, Drca N, Sadigh B, Jensen-Urstad M. Acute and long-term outcome of cryoablation therapy of typical atrioventricular nodal reentrant tachycardia. Europace. 2009;11:1077-1082. 
30. Feldman A, Voskoboinik A, Kumar S, Spence S, Morton JB, Kistler PM, Sparks PB, Vohra JK, Kalman JM. Predictors of acute and long-term success of slow pathway ablation for atrioventricular nodal reentrant tachycardia: A single center series of 1,419 consecutive patients. PACE. 2011;34:927-933. 
Table 1. Comparison of baseline characteristics between patients without vs. with AVNRT recurrence.

$\mathrm{AF}=$ Atrial Fibrillation; AET $=$ Atrial Ectopic Tachycardia; WPW= Wolff-Parkinson-White;

LVEF= Left Ventricular Ejection Fraction; AADs = antiarrhythmic drugs; AVNRT = AtrioVentricular Nodal Reetrant Tachycardia.

\begin{tabular}{|c|c|c|c|c|}
\hline & $\begin{array}{c}\text { Total } \\
(n=239)\end{array}$ & $\begin{array}{l}\text { No recurrence } \\
\quad(\mathrm{n}=211)\end{array}$ & $\begin{array}{l}\text { Recurrence } \\
\quad(\mathrm{n}=28)\end{array}$ & $\mathrm{p}$-value \\
\hline Males, n (\%) & $90(37.6)$ & $79(37.4)$ & $11(39.3)$ & 0.85 \\
\hline Age, years & $47.5 \pm 19.7$ & $48.4 \pm 19.5$ & $41 \pm 20.1$ & 0.06 \\
\hline Hypertension, n (\%) & $57(23.8)$ & $52(24.6)$ & $5(17.8)$ & 0.42 \\
\hline Hyperthyroidism, n (\%) & $5(2.1)$ & $5(2.4)$ & $0(0.0)$ & 0.41 \\
\hline Hypothyroidism, n (\%) & $13(5.4)$ & $10(4.7)$ & $3(10.7)$ & 0.19 \\
\hline Structural heart disease, $\mathrm{n}(\%)$ & $18(7.5)$ & $15(7.1)$ & $3(10.7)$ & 0.49 \\
\hline Associated arrhythmias, n (\%) & $22(9.2)$ & $20(9.5)$ & $2(7.1)$ & 1.00 \\
\hline $\mathrm{AF}, \mathrm{n}$ & 15 & 15 & 0 & 0.13 \\
\hline $\mathrm{AET}, \mathrm{n}$ & 2 & 2 & 0 & 0.60 \\
\hline WPW, n & 1 & 0 & 1 & 0.11 \\
\hline Atrial Flutter, $\mathrm{n}$ & 1 & 1 & 0 & 0.11 \\
\hline AV block, $n$ & 2 & 2 & 0 & 0.60 \\
\hline $\operatorname{LVEF}(\%)$ & $61.5 \pm 6.6$ & $61.2 \pm 7.2$ & $62.6 \pm 7.2$ & 0.50 \\
\hline \multicolumn{5}{|l|}{ AADs } \\
\hline Class IC, $\mathrm{n}(\%)$ & $48(20.1)$ & $44(20.8)$ & $4(14.3)$ & 0.38 \\
\hline Beta-blockers, n (\%) & $107(44.7)$ & $94(44.5)$ & $13(46.4)$ & 0.85 \\
\hline Calcium-channel blockers, n (\%) & $25(10.5)$ & $22(10.4)$ & $3(10.7)$ & 0.96 \\
\hline
\end{tabular}




\begin{tabular}{|c|c|c|c|c|}
\hline Type of AVNRT & & & & \\
Typical, n (\%) & $227(94.9)$ & $201(95.3)$ & $26(92.8)$ & 0.58 \\
Atypical, n (\%) & $12(5.0)$ & $10(4.7)$ & $2(7.1)$ & 0.58 \\
\hline Symptomatic episodes /year, $\mathrm{n}$ & $24.9 \pm 52.6$ & $24.8 \pm 49.6$ & $25 \pm 70$ & 0.96 \\
\hline
\end{tabular}


Table 2. Comparison of baseline electrophysiological study parameters between patients without vs. with AVNRT recurrence.

$\mathrm{AA}=$ Atrial-atrial; $\mathrm{AH}=$ Atrial-His $; \mathrm{HV}=$ His-Ventricular; AVNERP= Atrio-Ventricular Node Effective Refractory Period; AVNRT= Atrio-Ventricular Nodal Reentrant Tachycardia; WBCL= Wenckebach block cycle length.

\begin{tabular}{|c|c|c|c|}
\hline & $\begin{array}{l}\text { No recurrence } \\
\qquad(n=211)\end{array}$ & $\begin{array}{l}\text { Recurrence } \\
\qquad(n=28)\end{array}$ & p-value \\
\hline \multicolumn{4}{|l|}{ Baseline intervals } \\
\hline $\mathrm{AA},(\mathrm{ms})$ & $829.8 \pm 163.41$ & $738 \pm 172.3$ & 0.01 \\
\hline $\mathrm{AH},(\mathrm{ms})$ & $86 \pm 27$ & $80.6 \pm 26.5$ & 0.37 \\
\hline $\mathrm{HV},(\mathrm{ms})$ & $42.8 \pm 8.7$ & $46.4 \pm 8.9$ & 0.82 \\
\hline Sustained AVNRT induction, n (\%) & $182(86.2)$ & $21(75)$ & 0.19 \\
\hline \multicolumn{4}{|l|}{ Programmed ventricular stimulation } \\
\hline AVNERP, (ms) & $271.3 \pm 75.6$ & $280 \pm 90$ & 0.60 \\
\hline AH Jump, n (\%) & $29(13.7)$ & $3(10.7)$ & 0.69 \\
\hline AVNRT induction, $\mathrm{n}(\%)$ & $6(2.8)$ & $0(0.0)$ & 0.37 \\
\hline AVNRT induction on isoproterenol, $\mathrm{n}(\%)$ & $0(0.0)$ & $0(0.0)$ & - \\
\hline \multicolumn{4}{|l|}{ Programmed atrial stimulation } \\
\hline AVNERP, (ms) & $278.9 \pm 74.5$ & $257.8 \pm 47.7$ & 0.30 \\
\hline AH Jump, n (\%) & $202(95.7)$ & $24(85.7)$ & 0.12 \\
\hline AVNRT induction, $\mathrm{n}(\%)$ & $133(63)$ & $14(50)$ & 0.16 \\
\hline AVNRT induction on isoproterenol, $\mathrm{n}(\%)$ & $43(20.4)$ & $7(25)$ & 0.84 \\
\hline Incremental atrial pacing & & & \\
\hline
\end{tabular}


WBCL, ms

$356.9 \pm 76.3$

\begin{tabular}{l|l}
$325.4 \pm 54.02$ & 0.05
\end{tabular}

Crossover sign, n (\%)

76 (36)

13 (46.4)

0.44 
Table 3. Comparison of cooling dynamics parameters between patients without vs. with AVNRT recurrence. $\mathrm{T}=$ temperature; AVNRT: atrioventricular node reentrant tachycardia.

\begin{tabular}{|l|c|c|c|c|}
\hline & Total & No recurrence & Recurrence \\
$(\mathrm{n}=239)$ & $(\mathrm{n}=211)$ & $\mathrm{n}=28)$ & \\
\hline Cryoenergy applications, $\mathrm{n}$ & $3.3 \pm 2.8$ & $3.2 \pm 2.9$ & $3.6 \pm 2.4$ & 0.54 \\
\hline Ineffective applications, $\mathrm{n}$ & $1.4 \pm 1.9$ & $1.2 \pm 1.7$ & $1.7 \pm 1.4$ & 0.45 \\
\hline Duration of cryoablation, min & $18.9 \pm 10.3$ & $18.8 \pm 10.6$ & $19.5 \pm 8.7$ & 0.49 \\
\hline Effective Cryoenergy application & & & & \\
Duration, min & $7.9 \pm 0.5$ & $7.9 \pm 0.4$ & $7.7 \pm 0.7$ & 0.13 \\
$\quad$ Time to reach T Ò-70 ${ }^{\circ} \mathrm{C}$, sec & $7.5 \pm 2.9$ & $7.3 \pm 2.5$ & $8.9 \pm 4.4$ & 0.03 \\
$\quad$ Minimal absolute temperature, ${ }^{\circ} \mathrm{C}$ & $-79.0 \pm 2.4$ & $-79.2 \pm 2.3$ & $-78.0 \pm 2.5$ & 0.04 \\
$\quad$ Cooling curve inversion, $\mathrm{n}(\%)$ & $36(15)$ & $30(14.2)$ & $6(21.4)$ & 0.74 \\
\hline Fluoroscopy time, min & $4.5 \pm 5.0$ & $4.8 \pm 5.3$ & $2.8 \pm 2.8$ & 0.25 \\
\hline
\end{tabular}


Table 4. Comparison of post-ablation electrophysiological study parameters between patients without vs. with AVNRT recurrence. * = cryomodulation of the AV nodal slow pathway. $\mathrm{AA}=$ Atrial-Atrial; $\mathrm{AH}=$ Atrial-His $; \mathrm{HV}=$ His-Ventricular; $\mathrm{AVNERP}=$ AtrioVentricular Node Effective Refractory Period; AVNRT= Atrio-Ventricular Nodal Reentrant Tachycardia; WBCL= Wenckebach block cycle length.

\begin{tabular}{|c|c|c|c|}
\hline & $\begin{array}{l}\text { No recurrence } \\
\qquad(\mathrm{n}=211)\end{array}$ & $\begin{array}{l}\text { Recurrence } \\
\qquad(n=28)\end{array}$ & $\mathrm{p}$-value \\
\hline \multicolumn{4}{|l|}{ Baseline intervals } \\
\hline $\mathrm{AA},(\mathrm{ms})$ & $826 \pm 187.8$ & $843 \pm 204.8$ & 0.83 \\
\hline $\mathrm{AH},(\mathrm{ms})$ & $87 \pm 31.3$ & $92.2 \pm 33.4$ & 0.65 \\
\hline $\mathrm{HV},(\mathrm{ms})$ & $44.3 \pm 7.9$ & $49 \pm 7.4$ & 0.15 \\
\hline \multicolumn{4}{|l|}{ Programmed ventricular stimulation } \\
\hline AVNERP, (ms) & $282 \pm 62$ & $290 \pm 60$ & 0.23 \\
\hline AH Jump, n (\%) & $2(0.9)$ & $0(0.0)$ & 0.13 \\
\hline AVNRT induction, $\mathrm{n}(\%)$ & $0(0.0)$ & $0(0.0)$ & - \\
\hline AVNRT induction on isoproterenol, $\mathrm{n}(\%)$ & $0(0.0)$ & $0(0.0)$ & - \\
\hline \multicolumn{4}{|l|}{ Programmed atrial stimulation } \\
\hline AVNERP, (ms) & $312.6 \pm 77.5$ & $261.8 \pm 63.7$ & 0.04 \\
\hline AH Jump, n (\%) & $42(19.9)$ & $9(32.1)$ & 0.13 \\
\hline AVNRT induction, $\mathrm{n}(\%)$ & $1 *(0.5)$ & $0(0.0)$ & 0.72 \\
\hline AVNRT induction on isoproterenol, $\mathrm{n}(\%)$ & $0(0.0)$ & $0(0.0)$ & - \\
\hline AV nodal single echo beat $\mathrm{n}(\%)$ & $18(8.5)$ & $1(3.6)$ & 0.38 \\
\hline \multicolumn{4}{|l|}{ Incremental atrial pacing } \\
\hline WBCL, ms & $375.5 \pm 82.5$ & $332 \pm 69.6$ & $<0.01$ \\
\hline
\end{tabular}


Kay sign, n (\%)

$6(2.8)$

3 (10.7)

0.03 
Table 5. Multivariate analysis of parameters related to long-term recurrence.

$\mathrm{AA}=$ Atrial-Atrial; $\mathrm{WBCL}=\mathrm{Wenckebach}$ block cycle length $\mathrm{AVNERP}=$ atrioventricular node effectice refractory period. OR: odds ratio. CI: confidence interval.

\begin{tabular}{|l|c|c|c|}
\hline & OR & $95 \%$ CI & p-value \\
\hline Baseline AA interval, pre-ablation & 0.99 & $0.98-1.00$ & 0.28 \\
\hline WBCL, pre-ablation & 0.98 & $0.97-1.003$ & 0.13 \\
\hline WBCL, post-ablation & 0.98 & $0.97-1.002$ & 0.10 \\
\hline Time to reach T O-70 ${ }^{\circ} \mathrm{C}$ & 1.75 & $1.01-3.03$ & 0.04 \\
\hline Minimal temperature reached & 0.12 & $0.87-3.13$ & 0.12 \\
\hline Persistence of Kay sign & 19.54 & $0.89-428.83$ & 0.06 \\
\hline AVNERP, post-ablation & 1.00 & $0.98-1.02$ & 0.64 \\
\hline
\end{tabular}




\section{Figure legends}

Figure 1. Kaplan-Meier estimate of freedom from arrhythmic recurrence of patients undergoing AVNRT cryoablation, stratified for the residual presence of none, one or two markers of dual AV node physiology (AV nodal single echo beat, AH Jump and Kay sign).

Figure 2. Distribution of time intervals to reach target temperature $\left(-70^{\circ} \mathrm{C}\right)$ among the study population. Median, interquartile range and minimum/maximum values are represented both for patients without recurrence $(n=211)$ and for patients with recurrence $(n=28)$.

Figure 3. Comparison between cooling dynamic curves (starting from cryomapping at $-30^{\circ} \mathrm{C}$ to cryoablation at $-70^{\circ} \mathrm{C}$ ) of two different patients respectively experiencing long-term freedom from arrhythmias (light-blue) and early AVNRT recurrence (blue). 
Figure 1.

Markers of residual AV node physiology

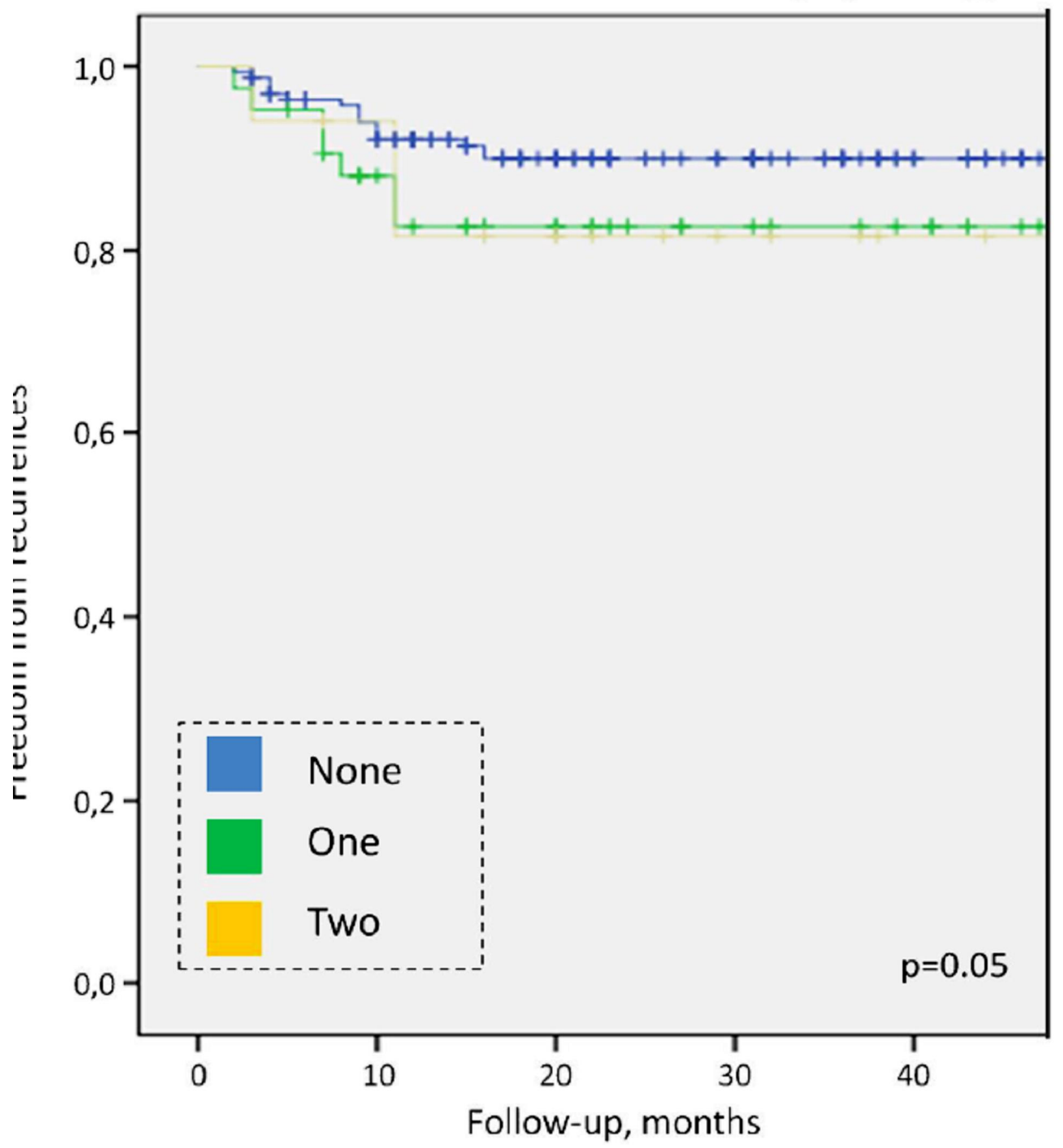


Figure 2.

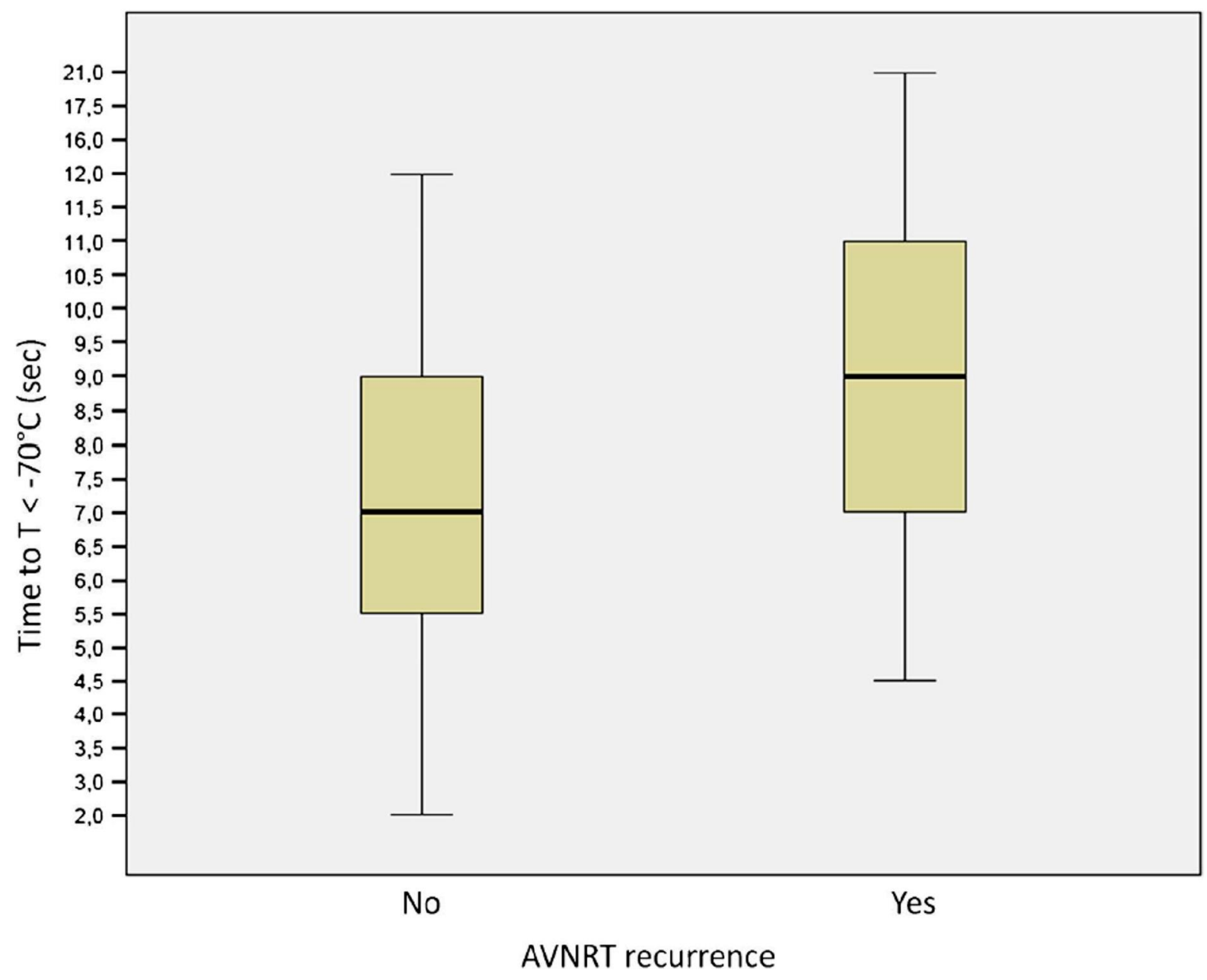


Figure 3.

Cooling Curves

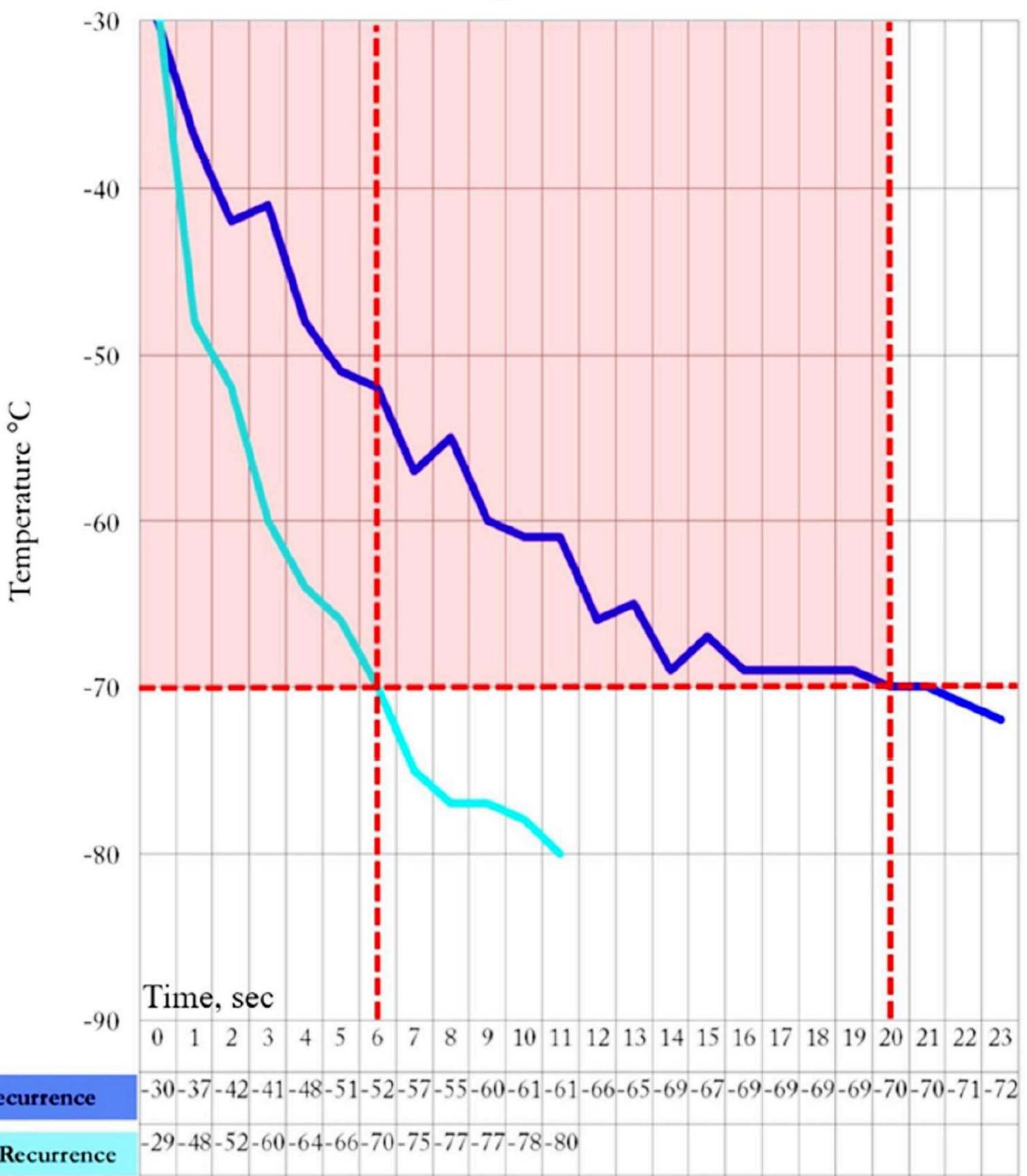

